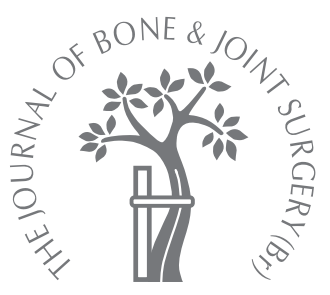

J. S. Shim, H. P. Jang

From Sungkyunkwan University School of Medicine, Seoul, Korea

J. S. Shim, MD, PhD,

Professor

H. P. Jang, MD, Fellow Department of Orthopedic Surgery

Samsung Medical Center, Sungkyunkwan University School of Medicine, 50 IL-Won Dong, Kang Nam Ku, Seoul 135-710, Korea.

Correspondence should be sent to $\mathrm{Dr}$ J. S. Shim; e-mail: jss3505@skku.edu

(C2008 British Editorial Society of Bone and Joint Surgery doi:10.1302/0301-620X.90B7. $20339 \$ 2.00$

$J$ Bone Joint Surg $[\mathrm{Br}]$ 2008;90-B:934-9.

Received 15 October 2007;

Accepted after revision 6 March 2008

\title{
Operative treatment of congenital torticollis
}

There were 47 patients with congenital muscular torticollis who underwent operative release. After a mean follow-up of 74 months (60 to 90 ), they were divided into two groups, one aged one to four years (group 1) and the other aged five to 16 years (group 2). The outcomes were assessed by evaluating the following parameters: deficits of lateral flexion and rotation, craniofacial asymmetry, surgical scarring, residual contracture, subjective evaluation and degree of head tilt.

The craniofacial asymmetry, residual contracture, subjective evaluation and overall scores were similar in both groups. However, group 2 showed superior results to group 1 in terms of the deficits of movement, surgical scarring and degree of head tilt.

It is recommended that operative treatment for congenital muscular torticollis is postponed until the patient can comply successfully with post-operative bracing and an exercise programme.

There is controversy regarding the aetiology of congenital muscular torticollis. Birth trauma, intrauterine malposition, infection, and venous occlusion have all been implicated. ${ }^{1,2}$ Treatments include observation, the use of orthotics, exercise programmes, traction, and various operations. ${ }^{3-6}$ These include subcutaneous tenotomy, open tenotomy, bipolar tenotomy, and radical resection of a sternomastoid tumour or the sternocleidomastoid muscle. ${ }^{1,3,5,7-10}$

The optimal time for operative treatment is contentious. Since Chandler and Altenberg ${ }^{3}$ first described one to four years of age as optimal, several authors, including Ling, ${ }^{5}$ have supported this idea. Coventry and Harris ${ }^{4}$ extended the recommended age of treatment up to 12 years. Ippolito, Tudisco and Massobrio $^{11}$ and Lee, Kang and Bose ${ }^{12}$ reported successful operative treatment on patients under 12 years. Previous accounts considered age to be the most important factor influencing outcome, and most authors agree that the prognosis is better if surgery is performed earlier, particularly under the age of four.

This retrospective study investigated the optimal time for operative treatment of congenital muscular torticollis by analysing a number of clinical parameters in two patient groups (younger or older than four years of age), who underwent release of the sternocleidomastoid muscle.

\section{Materials and Methods}

Between October 1994 and December 2000, 50 children had surgery for congenital muscular torticollis at our institution. The condition had either recurred after physiotherapy and stretching exercises, or was not diagnosed until at least one year of age. Three were lost to follow-up. Physical examinations were carried out pre-operatively and at the last follow-up visit. The range of movement of the neck was measured at least twice with a goniometer by one of the authors (JSS) and the mean values summarised. Plain radiographs of the cervical spine and the medical records of 47 patients (28 males, 19 females) were evaluated. A total of 22 patients were under four years of age at operation and 25 were older. The mean age at operation was six years (22 months to 16 years). The right side was affected in 32 patients and the left in 15. Either a unipolar (37 cases) or a bipolar (ten cases) release was performed as the primary operation in all cases (Table I). ${ }^{5,8-10}$

Under general anaesthesia, the patients lay supine with the head turned away from the affected side. In unipolar release, a complete resection was performed at the sternal and clavicular insertions of the sternocleidomastoid. The platysma, adjacent fascia and any other tight soft tissues were also resected. When necessary, the omohyoid, anterior scalene muscles and residual bands of the fascia were released 
Table I. Case analysis

\begin{tabular}{|c|c|c|c|c|c|c|c|c|}
\hline & \multicolumn{2}{|c|}{ Gender } & \multirow[b]{2}{*}{ Age in yrs (range) } & \multicolumn{2}{|c|}{ Side affected } & \multicolumn{2}{|c|}{ Operative technique } & \multirow[b]{2}{*}{ Follow-up in mths (range) } \\
\hline & M & $\mathbf{F}$ & & Right & Left & Unipolar & Bipolar & \\
\hline \multicolumn{9}{|c|}{ Group } \\
\hline 1 & 13 & 9 & 2.8 (22 mths to 4 yrs) & 15 & 7 & 22 & 0 & 75 (64 to 90$)$ \\
\hline 2 & 15 & 10 & $8.9(5$ to 16$)$ & 17 & 8 & 15 & 10 & 74 (60 to 90$)$ \\
\hline
\end{tabular}

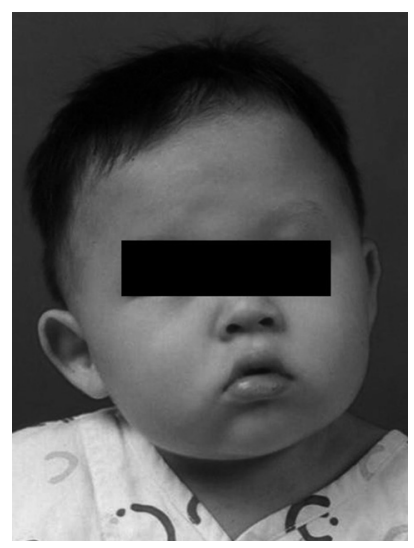

Fig. 1a

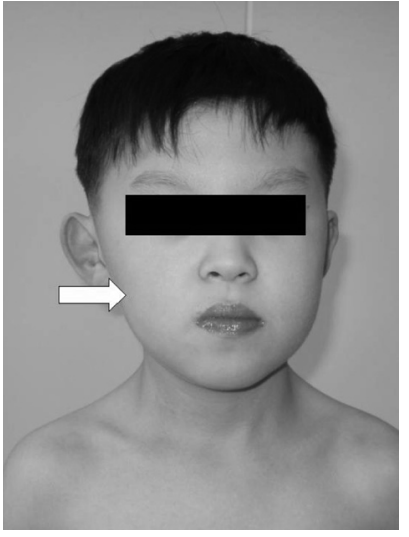

Fig. 1c

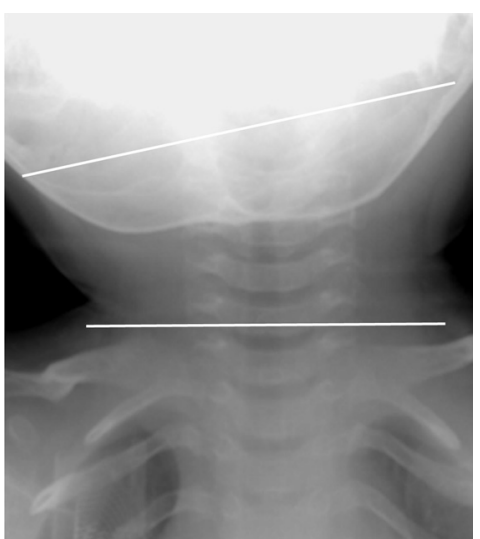

Fig. 1b

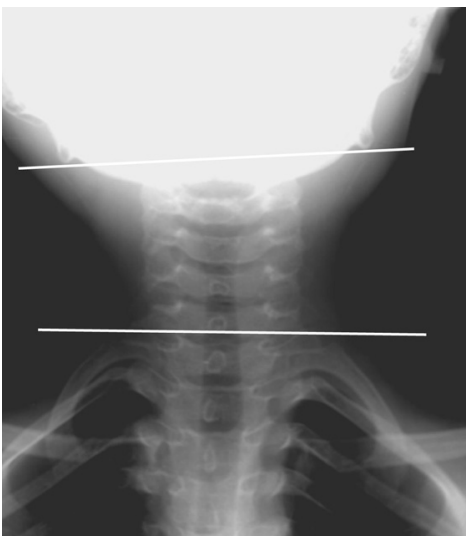

Fig. 1d

A 30-month-old child with a right congenital muscular torticollis. a) Pre-operative photograph and b) simple radiograph. The pre-operative cervicomandibular angle was $10^{\circ}$, c) Postoperative photograph and d) simple radiograph. Six years after unipolar tenotomy the postoperative cervicomandibular angle was $1^{\circ}$. The overall result was good and the patient's head was restored to the neutral position, but facial asymmetry (arrow) remained.

to achieve overcorrection. ${ }^{5,9,10}$ Bipolar release of the sternocleidomastoid was performed at its origin from the mastoid process when the deformity was so severe that it could not be corrected by manipulation after unipolar release. In such cases the platysma and adjacent fascia were resected completely. ${ }^{9,10}$ Five days post-operatively, neck-stretching exercises were begun and sutures were removed at one week. A brace was then applied for six to eight hours a day for a mean of eight weeks (4 to 13 ) to maintain a slightly overcorrected position, with the chin tilted toward the affected side and the head tilted toward the contralateral side. The patients were educated in performing stretching exercises for at least ten minutes, four to six times daily.

The patients were divided into two groups, those aged between one and four years (group 1, mean age 2.8 years) and those between five and 16 years (group 2, mean age 8.9 
Table II. Scoring of overall results (modified from Cheng and Tang ${ }^{2}$ )

\begin{tabular}{|c|c|c|c|c|}
\hline Overall results & $\begin{array}{l}\text { Excellent } \\
\text { ( } 3 \text { points) }\end{array}$ & $\begin{array}{l}\text { Good } \\
\text { ( } 2 \text { points) }\end{array}$ & $\begin{array}{l}\text { Fair } \\
\text { (1 point) }\end{array}$ & $\begin{array}{l}\text { Poor } \\
\text { (0 points) }\end{array}$ \\
\hline Rotational deficit $\left({ }^{\circ}\right)$ & $\leq 5$ & 6 to 10 & 11 to 15 & $>15$ \\
\hline Craniofacial asymmetry (none, mild, moderate, severe) & None & Mild & Moderate & Severe \\
\hline Scar (none, mild, moderate, severe) & None & Mild & Moderate & Severe \\
\hline Residual contracture (none, lateral, clavicular, sternal) & None & Lateral & Lateral, clavicular & Clavicular, sternal \\
\hline Head tilt $\left(^{\circ}\right)\left(\mathrm{CMA}^{*}\right)$ & $\leq 5$ & 6 to 10 & 11 to 15 & $>15$ \\
\hline Overall scores & 17 to 21 & 12 to 16 & 7 to 11 & $<7$ \\
\hline
\end{tabular}

* CMA, cervicomandibular angle

Table III. Results of treatment

\begin{tabular}{|c|c|c|c|c|c|c|c|c|c|}
\hline & \multicolumn{3}{|c|}{ Mean lateral flexion deficit $\left({ }^{\circ}\right)$} & \multicolumn{3}{|c|}{ Mean rotational deficit $\left({ }^{\circ}\right)$} & \multicolumn{3}{|c|}{ Mean angle of head tilt $\left(\mathrm{CMA}^{*}\right)\left(^{\circ}\right)$} \\
\hline & Pre-operative & Post-operative & Difference & Pre-operative & Post-operative & Difference & Pre-operative & Post-operative & Difference \\
\hline All patients & $13.6(10$ to 20$)$ & $2.1(0$ to 5$)$ & 11.5 & $5.3(0$ to 10$)$ & $1.1(0$ to 5$)$ & 4.2 & 10.8 (5.8 to 21.3$)$ & $3.3(0$ to 6.2$)$ & 7.5 \\
\hline \multicolumn{10}{|l|}{ Group } \\
\hline 1 & $11.8(10$ to 15$)$ & $2.0(0$ to 5$)$ & 9.8 & $3.6(0$ to 10$)$ & $1.1(0$ to 5$)$ & 2.5 & $8.4(5.8$ to 13$)$ & $4.0(0$ to 6.2$)$ & 4.4 \\
\hline 2 & 15.2 (10 to 20$)$ & $2.2(0$ to 5$)$ & 13.0 & $6.8(5$ to 10$)$ & $1.0(0$ to 5$)$ & 5.8 & 12.9 (8.5 to 21.3$)$ & $2.7(0$ to 4.5$)$ & 10.2 \\
\hline $\mathrm{p}$-value & & & $0.0167^{\dagger}$ & & & $0.002^{\dagger}$ & & & $<0.0001^{\ddagger}$ \\
\hline
\end{tabular}

years). The 22 patients in group 1 had all undergone unipolar release. In group 2 there were 25 patients; unipolar release was performed in 15 and bipolar release in ten. The mean period of follow-up in groups 1 and 2 was 75 months (64 to 90) and 74 months (60 to 90), respectively. The total mean follow-up was for 74 months (60 to 90) (Table I).

At the final review, the outcome was assessed by measuring the lateral bending and rotational deficits, degree of head tilt, craniofacial asymmetry, cosmetic and functional satisfaction, surgical scarring, and any residual contracture. Craniofacial asymmetry was observed by comparing the two sides for differences in the size of the malar eminence, the size of the chin, loss of the column of the sternocleidomastoid muscle, flattening of the occiput, the degree of facial asymmetry, the deviation of the eye and nose to the affected side and prominence of the mastoid process.

The cervicomandibular angle was measured from an anteroposterior radiograph of the cervical spine of each patient at final follow-up to quantify the degree of head tilt. ${ }^{13}$ It was defined as the angle between a line along the upper border of the $\mathrm{C} 7$ vertebral body and a line connecting the lower margins of the mandibular angles (Fig. 1). The head tilt was classified as 'excellent' $\left(<5^{\circ}\right)$, 'good' $\left(6^{\circ}\right.$ to $\left.10^{\circ}\right)$, 'fair' $\left(11^{\circ}\right.$ to $\left.15^{\circ}\right)$, or 'poor' $\left(>15^{\circ}\right)$. The clinical results were evaluated using the scoring system of Cheng and Tang, ${ }^{2}$ with an additional assessment of the cervicomandibular angle (Table II). The operations (uni- or bipolar release) were assessed by subdividing group 2 into $2 \mathrm{~A}$ (unipolar tenotomy in 15 patients) and 2B (bipolar tenotomy in ten patients).

Comparative analysis of the deficits of lateral flexion and rotational movement of the neck were carried out using Wilcoxon's two-sample test. The cervicomandibular angles were compared using a paired $t$-test. The overall Cheng and Tang $^{2}$ scores were compared using a chi-squared test and functional satisfaction was assessed using Fisher's exact test. Craniofacial asymmetry, scarring, cosmetic satisfaction and residual contracture were analysed and compared using the Cochran-Mantel-Haenszel test.

\section{Results}

The mean lateral flexion deficit of the neck improved from $13.6^{\circ}\left(10^{\circ}\right.$ to $\left.20^{\circ}\right)$ pre-operatively to $2.1^{\circ}\left(0^{\circ}\right.$ to $\left.5^{\circ}\right)$ postoperatively, demonstrating a mean improvement of $11.5^{\circ}$ (group 1: $9.8^{\circ}$, group 2: $13.0^{\circ}$ ). The latter showed more significant improvement than did group $1(\mathrm{p}=0.0167)$. The mean rotational deficit improved from $5.3^{\circ}\left(0^{\circ}\right.$ to $\left.15^{\circ}\right)$ preoperatively to $1.1^{\circ}\left(0^{\circ}\right.$ to $\left.5^{\circ}\right)$ post-operatively, demonstrating a mean improvement of $4.2^{\circ}$ (group $1: 2.5^{\circ}$, group 2: $\left.5.8^{\circ}\right)$. Again, group 2 demonstrated more significant improvement than did group $1(p=0.002)$. The mean cervicomandibular angle improved from $10.8^{\circ}\left(5.8^{\circ}\right.$ to $\left.21.3^{\circ}\right)$ pre-operatively to $3.3^{\circ}\left(0^{\circ}\right.$ to $\left.6.2^{\circ}\right)$ post-operatively, a mean improvement of $7.5^{\circ}$ (group 1: $4.4^{\circ}$, group 2: 
Table IV. Treatment results

\begin{tabular}{|c|c|c|c|c|c|c|c|}
\hline \multirow[b]{2}{*}{ Overall results } & \multicolumn{3}{|l|}{ Group 1} & \multicolumn{3}{|l|}{ Group 2} & \multirow[b]{2}{*}{ p-value } \\
\hline & Excellent & Good & Fair & Excellent & Good & Fair & \\
\hline Craniofacial asymmetry (none, mild, moderate, severe) & 13 & 7 & 2 & 9 & 14 & 2 & $0.2429^{*}$ \\
\hline Scar (none, mild, moderate, severe) & 9 & 9 & 4 & 18 & 7 & - & $0.0101^{*}$ \\
\hline Residual contracture (none, lateral, clavicular, sternal) & 7 & 14 & 1 & 12 & 12 & 1 & $0.3139^{*}$ \\
\hline Cosmetic satisfaction & 7 & 13 & 2 & 15 & 9 & 1 & $0.0636^{*}$ \\
\hline Functional satisfaction & 16 & 6 & - & 21 & 4 & - & $0.4796^{\dagger}$ \\
\hline Overall scores & 14 & 8 & - & 19 & 6 & - & $0.3551^{\ddagger}$ \\
\hline
\end{tabular}

$\left.10.2^{\circ}\right)$, with the latter showing a more significant difference than group 1 ( $\mathrm{p}<0.0001$, Table III).

With regard to improvement in craniofacial asymmetry, there were 13 excellent, seven good, and two fair results in group 1 and nine excellent, 14 good and two fair results in group 2, with no significant difference between the groups $(p=0.2429)$. Evaluation of scar tissue showed nine excellent, nine good and 4 fair results in group 1 and 18 excellent and seven good results in group 2 . The latter demonstrated significantly better results than group $1(\mathrm{p}=0.0101)$. The residual appearance of the sternomastoid showed seven excellent, 14 good and one fair result in group 1 and 12 excellent, 12 good and one fair result in group 2, with no significant difference between the groups $(\mathrm{p}=0.3139)$. The level of cosmetic satisfaction was seven excellent, 13 good and two fair results in group 1 and 15 excellent, nine good and one fair in group 2 with no significant difference between the groups $(p=0.0636)$. The level of functional satisfaction in group 1 was excellent and good in 16 and six patients, respectively. In group 2 it was excellent and good in 21 and four, respectively, with no significant difference between the groups $(\mathrm{p}=0.4796)$. The overall score was 14 excellent and eight good results in group 1 and 19 excellent and six good results in group 2, with no significant difference between the groups $(p=0.3551$, Table IV).

When comparing groups $2 \mathrm{~A}$ and $2 \mathrm{~B}$, there was no statistical difference in the improvement of neck movement and cervicomandibular angle, nor was there any significant difference in craniofacial asymmetry, scarring, cosmetic and functional satisfaction and overall scores between these subgroups $(\mathrm{p}>0.05)$.

\section{Discussion}

Traditionally, the operative treatment of congenital muscular torticollis has been largely determined by the age of the patient. Although some authors have suggested that operations should be performed within a few weeks of birth, ${ }^{1,14}$ later reports have shown spontaneous resolution of symptoms within a year of birth, ${ }^{9,15}$ or satisfactory results with conservative treatment, such as bracing, exercise and massage. ${ }^{4,6}$ An operation performed too early, particularly before one year of age creates problems in post-operative wound management owing to easier formation of haematomas and increased prevalence of infection. Therefore, some authors have reported that the optimal time for operation is between one and four years of age. ${ }^{3,5}$

Coventry and Harris ${ }^{4}$ reported that operation up to 12 years of age produced good results and this was supported by Lee et al. ${ }^{12}$ However, Canale, Griffin and Hubbard ${ }^{16}$ found better results in patients undergoing surgical release after ten years of age, but did not provide a sound reason for this finding. Minamitani, Inoue and Okuno ${ }^{17}$ and Chen and $\mathrm{Ko}^{18}$ also described excellent results in patients over six years of age, and the latter suggested that the degree of correction was affected by adequate surgical treatment and rehabilitation rather than age.

In this study, deficits of rotational movement and lateral flexion, the degree of head tilt (cervicomandibular angle) and evaluation of the scars were better in group 2, whereas other factors, including craniofacial asymmetry, were similar in both groups. There was no factor in which group 1 demonstrated superior results. Although preoperative rotational movement, deficits of the lateral flexion and head tilt were more severe in group 2, this group demonstrated better outcomes than group 1 . The degree of pre-operative deformity did not affect outcome.

Complete restoration of facial asymmetry is difficult in patients older than four years. ${ }^{5,7}$ However, Coventry and Harris ${ }^{4}$ suggested 12 years as the upper limit for good results. Although Arslan et al ${ }^{19}$ found excellent functional and cosmetic results after bipolar release at over six years of age, the recovery of facial asymmetry was unsatisfactory. In contrast, there was no difference in recovery of facial asymmetry between the groups in this study (Table IV, Figs 1 and 2).

Surgical scarring and loss of the sternocleidomastoid column are reported as generally more common in older patients. ${ }^{6}$ However, in this study, less scar tissue was found in the older children. We made incisions away from the clavicle and used subcutaneous sutures, and were thus able to produce less scar tissue, a result noted by others. ${ }^{5,6,16}$

Although there is controversy regarding the operative treatment, the most popular methods are uni- or bipolar 


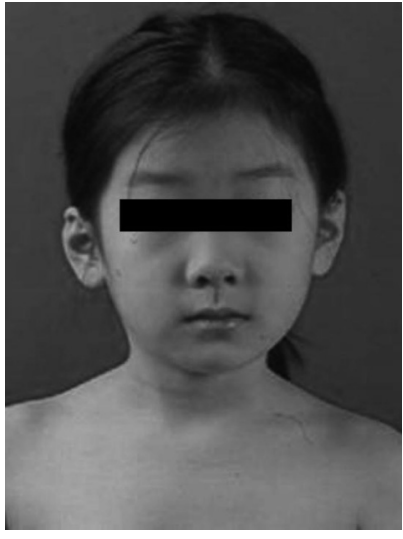

Fig. 2a

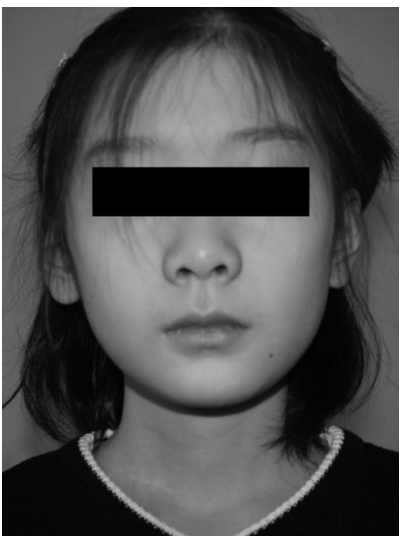

Fig. 2c

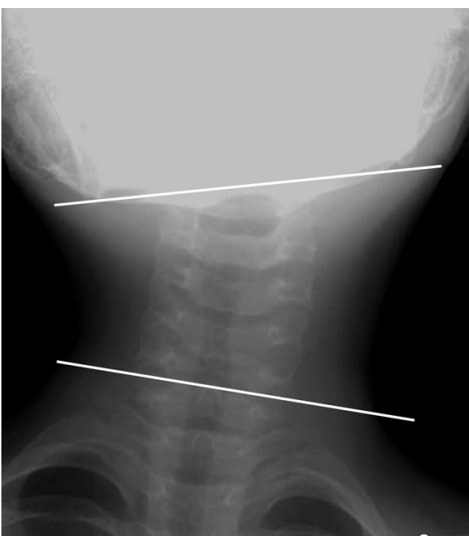

Fig. 2b

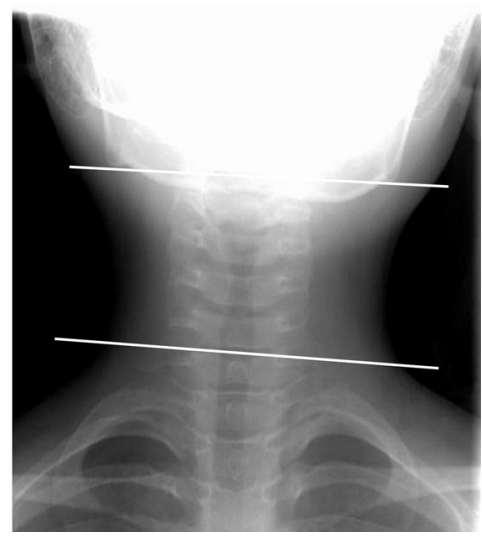

Fig. 2d

A six-year-old girl with right-sided congenital muscular torticollis. a) Pre-operative photograph and b) plain radiograph. The pre-operative cervicomandibular angle was $13^{\circ}$. c) Post-operative photograph and d) plain radiograph. Five years after unipolar tenotomy the cervicomandibular angle was $0^{\circ}$. The overall result was excellent and the patient's head was restored to the neutral position. The scar is almost invisible.

release..$^{8,9,20,21}$ The latter is reported to be superior in older patients with more severe deformity. ${ }^{18,19}$ In this study, the site of release was determined intra-operatively, with bipolar release undertaken when manipulation could not give adequate correction after unipolar release. Therefore, the results of those undergoing uni- or bipolar tenotomy were similar.

Post-operative immobilisation of the head and neck in an overcorrected position has been an important principle, and some authors recommended the application of a cast brace along with early exercise. Cheng and $\mathrm{Au}^{1}$ had good clinical results with post-operative bracing and rehabilitation in children older than two years. Ippolito et $\mathrm{al}^{11}$ suggested that a long-term Minerva cast could prevent recurrence.

The older age group in our study had a higher level of understanding of, and compliance with, the post-operative rehabilitation programme. In the younger age group, the fitting of a brace is difficult because of the short neck, abun- dance of soft tissue and poor compliance. Also, postoperative exercise is usually difficult in younger patients.

Our results suggest that age is not the most important factor when determining the optimal time for operation, and that compliance with a post-operative rehabilitation programme is the most important consideration. We suggest that operative treatment of congenital muscular torticollis should be delayed until such compliance is possible.

No benefits in any form have been received or will be received from a commercial party related directly or indirectly to the subject of this article.

\section{References}

1. Cheng JC, Au AW. Infantile torticollis: a review of 624 cases. J Pediatr Orthop 1994; 14:802-8

2. Cheng JC, Tang SP. Outcome of surgical treatment of congenital muscular torticollis. Clin Orthop 1999;362:190-200.

3. Chandler FA, Altenberg A. "Congenital" muscular torticollis. JAMA 1944;125:476-83.

4. Coventry MB, Harris LE. Congenital muscular torticollis in infancy: some observation regarding treatment. J Bone Joint Surg [Am] 1959;41-A:815-22.

5. Ling $\mathbf{C M}$. The influence of age on the results of open sternomastoid tenotomy in muscular torticollis. Clin Orthop 1976;116:142-8. 
6. Morrison DL, MacEwen GD. Congenital muscular torticollis: observation regarding clinical findings, associated conditions, and results of treatment. J Pediatr Orthop 1982;2:500-5.

7. Ferkel D, Westin GW, Dawson EG, Oppenheim WL. Muscular torticollis: a mod ified surgical approach. J Bone Joint Surg [Am] 1983;65-A:894-900.

8. Hellstadius A. Torticollis congenita. Acta Clin Scand 1972;62:586-9.

9. Hulbert KF. Congenital muscular torticollis. J Bone Joint Surg [Br] 1950;32-B:50-9.

10. Wirth CJ, Hagena FW, Wuelker N, Siebert WE. Biterminal tenotomy for the treat ment of congenital muscular torticollis: long-term results. J Bone Joint Surg [Am] 1992;74-A:427-34.

11. Ippolito E, Tudisco C, Massobrio M. Long-term results of open sternocleidomas toid tenotomy for idiopathic muscular torticollis. J Bone Joint Surg [Am] 1985;67A:30-8.

12. Lee EH, Kang YK, Bose K. Surgical correction of muscular torticollis in the older child. J Pediatr Orthop 1986;6:585-9.

13. Shim JS, Noh KC, Park SJ. Treatment of congenital muscular torticollis in patients older than 8 years. J Pediatr Orthop 2004;24:638-8.
14. Kieswetter WB, Nelson PK, Palladino VS, Koop CE. Neonatal torticollis. J Am Med Assoc 1955;157:1281-5.

15. Bernau A. Long-term results of operation for congenital muscular torticollis (authors transl). Z Orthop Ihre Grenzgeb 1977;115:875-90 (in German).

16. Canale ST, Griffin DW, Hubbard CN. Congenital muscular torticollis: a long-term follow-up. J Bone Joint Surg [Am] 1982;64-A:810-16.

17. Minamitani K, Inoue A, Okuno T. Results of surgical treatment of muscular torticollis for patients greater than 6 years of age. J Pediatr Orthop 1990;10:754-9.

18. Chen CE, Ko JY. Surgical treatment of muscular torticollis for patients above 6 years of age. Arch Orthop Trauma Surg 2000;120:149-51.

19. Arslan H, Gündüz S, Subasi M, Kesemenlin C, Necmioglu S. Frontal cephalometric analysis in the evaluation of facial asymmetry in torticollis, and outcomes of bipolar release in patients over 6 years of age. Arch Orthop Trauma Surg 2002;122:489-93.

20. Soeur R. Treatment of congenital torticollis. J Bone Joint Surg 1940;22:35-42.

21. Staheli LT. Muscular torticollis: late results of operative treatment. Surgery 1971;69:469-73. 